\title{
La educación en paisaje
}

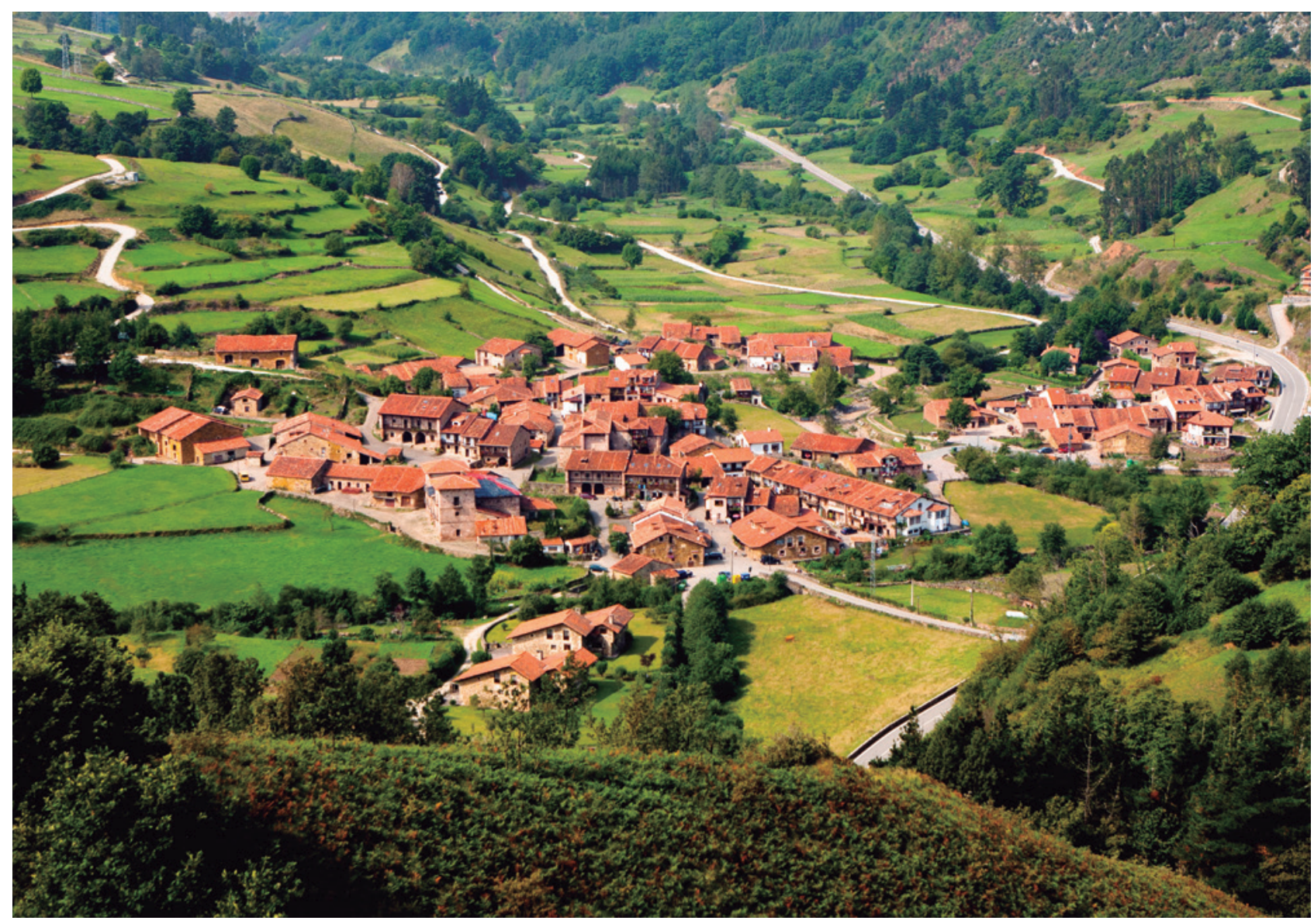

El presente artículo supone una breve reflexión acerca del concepto de paisaje, entendido como la percepción del territorio, y de la necesidad de contribuir a la formación de una

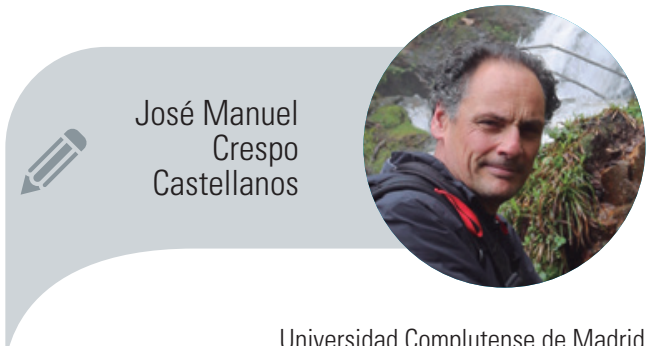

Universidad Complutense de Madrid josemanuelcrespo@edu.ucm.es sociedad consciente de que es un elemento esencial de la calidad de vida de las personas.

Desde una perspectiva educativa, supone un recurso didáctico idóneo para comprender las relaciones que la sociedad establece con el medio físico que habita. 


\section{La educación en paisaje}

En el año en curso se cumplen dos décadas de la firma en la ciudad de Florencia del Convenio Europeo del Paisaje (CEP), elaborado por el Consejo de Europa con el objetivo principal de promover la protección, gestión y ordenación de los paisajes y organizar la cooperación europea en este campo. Una de sus aportaciones de mayor relevancia es la de definir el concepto, hasta el momento intuitivo y polisémico, como "cualquier parte del territorio tal como la percibe la población, cuyo carácter es el resultado de la acción de factores naturales y/o humanos". Entiende por lo tanto paisaje como cualquier territorio, no solo aquellos de excepcional belleza, con valores ecológicos o culturales, sino también los más degradados y cotidianos, como los espacios urbanos, los industriales o los que perdieron su identidad.

El CEP parte de las siguientes premisas: "el paisaje desempeña un papel importante de interés general en los campos cultural, ecológico, medioambiental y social, y constituye un recurso favorable para la actividad económica y que su protección, gestión y ordenación pueden contribuir a la creación de empleo. Contribuye a la formación de las culturas Iocales y es un componente fundamental del patrimonio natural y cultural europeo, que coadyuva al bienestar de los seres humanos y a la consolidación de la identidad europea. Es un elemento importante de la calidad de vida de las poblaciones en todas partes: en los medios urbanos y rurales, en las zonas degradadas y de gran calidad, en los espacios de reconocida belleza y en los más cotidianos. La evolución de las técnicas de producción agrícola, forestal, industrial y minera, así como en materia de ordenación del territorio y urbanística, transporte, infraestructura, turismo y ocio y, a nivel más general, los cambios en la economía mundial están acelerando en muchos casos la transformación de los paisajes". Por estas razones el paisaje forma parte de los contenidos curriculares de las áreas de Ciencias Sociales y de la Naturaleza, en las diferentes etapas de la educación obligatoria y en la

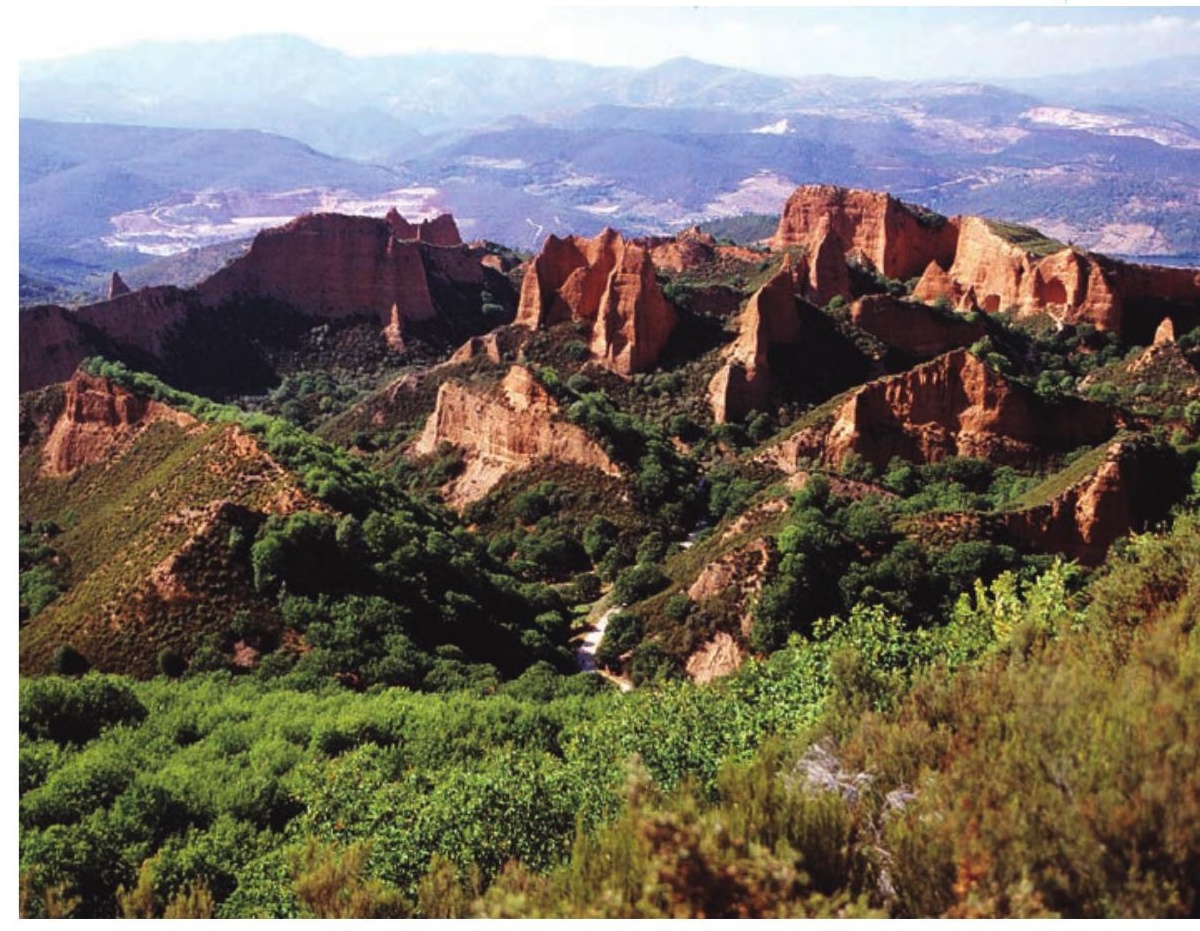

asignatura optativa de Geografía de Bachillerato. Surge así la necesidad de una educación en paisaje, entendida como el proceso de adquisición de una visión reflexiva y crítica que permita interpretar y valorar el espacio que se habita y percibe, pues el paisaje no es otra cosa que nuestra percepción del territorio. El filósofo Joan Manuel del Pozo considera al paisaje como un valor necesario de la existencia humana, íntimamente vinculado a dos de los cuatro valores esenciales del ser humano: la razón y la estética. Los otros dos valores son la ética y la bondad, con los que el paisaje se relaciona por ser una exigencia ética y moral. De acuerdo con ello, la educación debe contribuir con la formación de una ciudadanía, sensibilizada e implicada, que pueda valorar y participar en las actuaciones que se planteen sobre el territorio. Educar en paisaje es, por lo tanto, dotar de las herramientas necesarias para interpretar y comprender esa realidad individual y colectiva.

Fruto de la concienciación medioambiental y de la necesidad de alcanzar modelos de desarrollo sostenible aplicables a todas las dimensiones de la sociedad, la preocupación por el conocimiento, conservación, recuperación y mejora de los paisajes viene acrecentándose desde hace unas décadas. Como respuesta a las medidas planteadas en el CEP, en España se han aprobado leyes autonómicas 

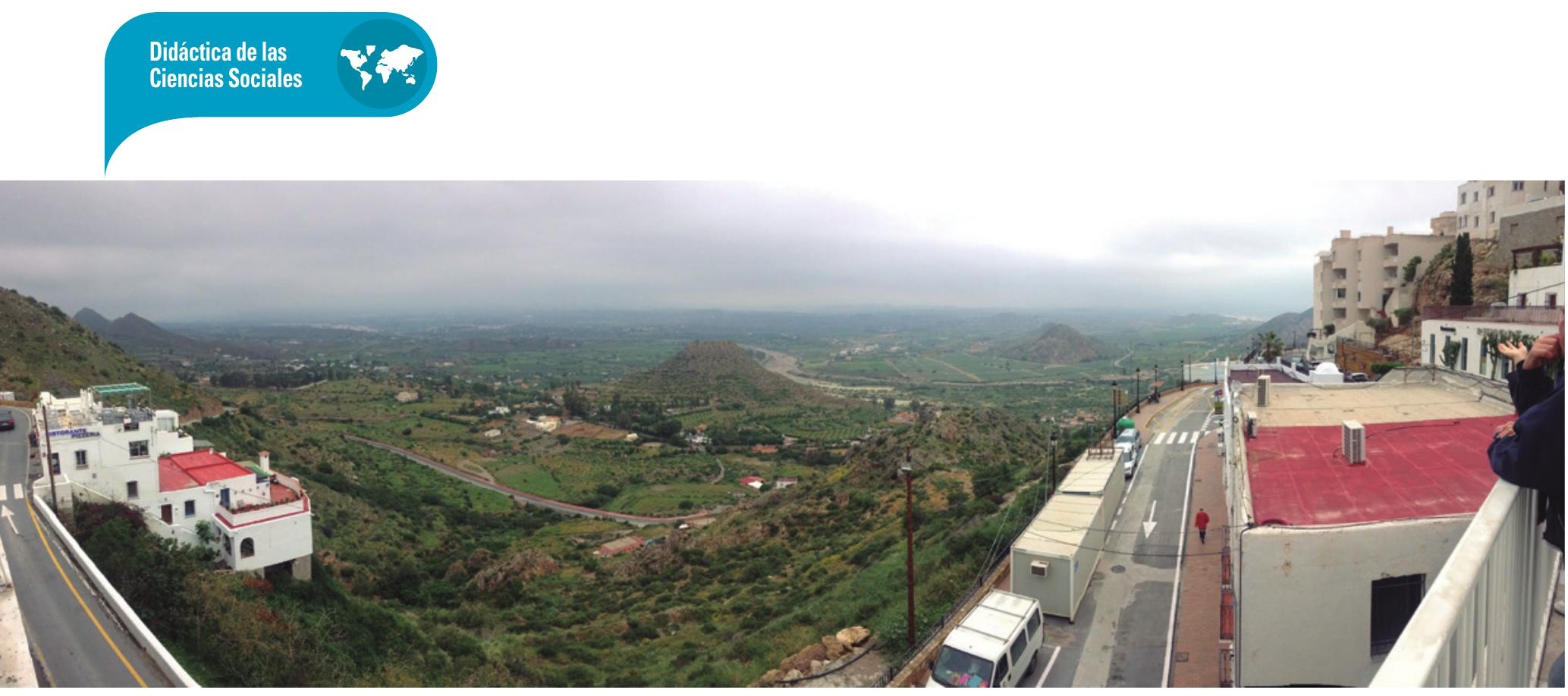

Mojácar (Almería). El paisaje es el resultado de la interacción sociedad-medio tal como lo percibe la población exclusivas en materia de paisaje como es el caso de la Comunidad Valenciana, Cataluña, Galicia, País Vasco y más recientemente, en 2014, Cantabria o la anunciada de Castilla La Mancha. En ellas se establecen objetivos y planes como la realización de catálogos, observatorios, la protección de paisajes relevantes y medidas específicas relacionadas con el artículo sexto del CEP: sensibilización y educación.

Además de su dimensión como elemento básico para la calidad de vida de las personas, los paisajes son recursos económicos. Los destinos vacacionales tienen su base en los valores territoriales turísticos, que pueden estar relacionados con la cultura, diversas actividades o el clima, pero mayoritariamente lo están con el paisaje. Prueba de ello es la creciente diversificación en los destinos de interior: rurales, naturaleza, deporte y aventura y culturales, frente al tradicional de sol y playa. Probablemente, la elección de un destino turístico se establece a partir de la decisión de conocer un paisaje imaginado. El turismo es, en consecuencia, una actividad que puede contribuir a la conservación del paisaje, e incluso con su recuperación, pero también supone un factor de pérdida de identidad y de sobrecarga para sistemas ambiental o socialmente frágiles, por lo que, como toda actividad económica, debe orientarse hacia modelos sostenibles.

\section{El paisaje como recurso didáctico}

El valor didáctico del paisaje reside en su carácter integrador, en la diversidad de elementos, factores y procesos que han intervenido en su configuración, así como en su doble dimensión, espaciotemporal por un lado, y objetiva y subjetiva por otro. Su interpretación supone una visión holística, práctica y realista del territorio y del papel que juegan sus diversos componentes, lo que conduce a la construcción de un conocimiento contextualizado. Su naturaleza no solo le confiere idoneidad como recurso didáctico para la enseñanza de la Geografía, sino que es posible acceder a su comprensión desde otras ciencias y empleando diferentes metodologías. El paisaje es tanto recurso como objeto de estudio en sí mismo, lo que hace de él un vehículo idóneo para comprender conceptos geográficos, desarrollar capacidades procedimentales y adoptar aptitudes de respeto y valoración. Si aprender es el recurso de la inteligencia para sobrevivir en un mundo cambiante, entonces comprender y conocer los paisajes ha de ser un objetivo de primer orden para la educación geográfica.

Así, los paisajes como recurso didáctico para la educación geográfica presentan las siguientes ventajas:

入 Diversidad de elementos, tanto físicos como humanos, en él se sintetizan la mayor parte de los conceptos geográficos. Su estudio conlleva una visión integral de las distintas ramas de la Geografía: climatología, geomorfología, edafología, biogeografía, demografía, etc. Del mismo modo precisa de la aportación de otras miradas: desde la geología, la ecología, la historia, la literatura o el arte, entre otras.

$\boldsymbol{7}$ Toda persona posee imágenes de paisajes y sentimiento de pertenencia hacia 

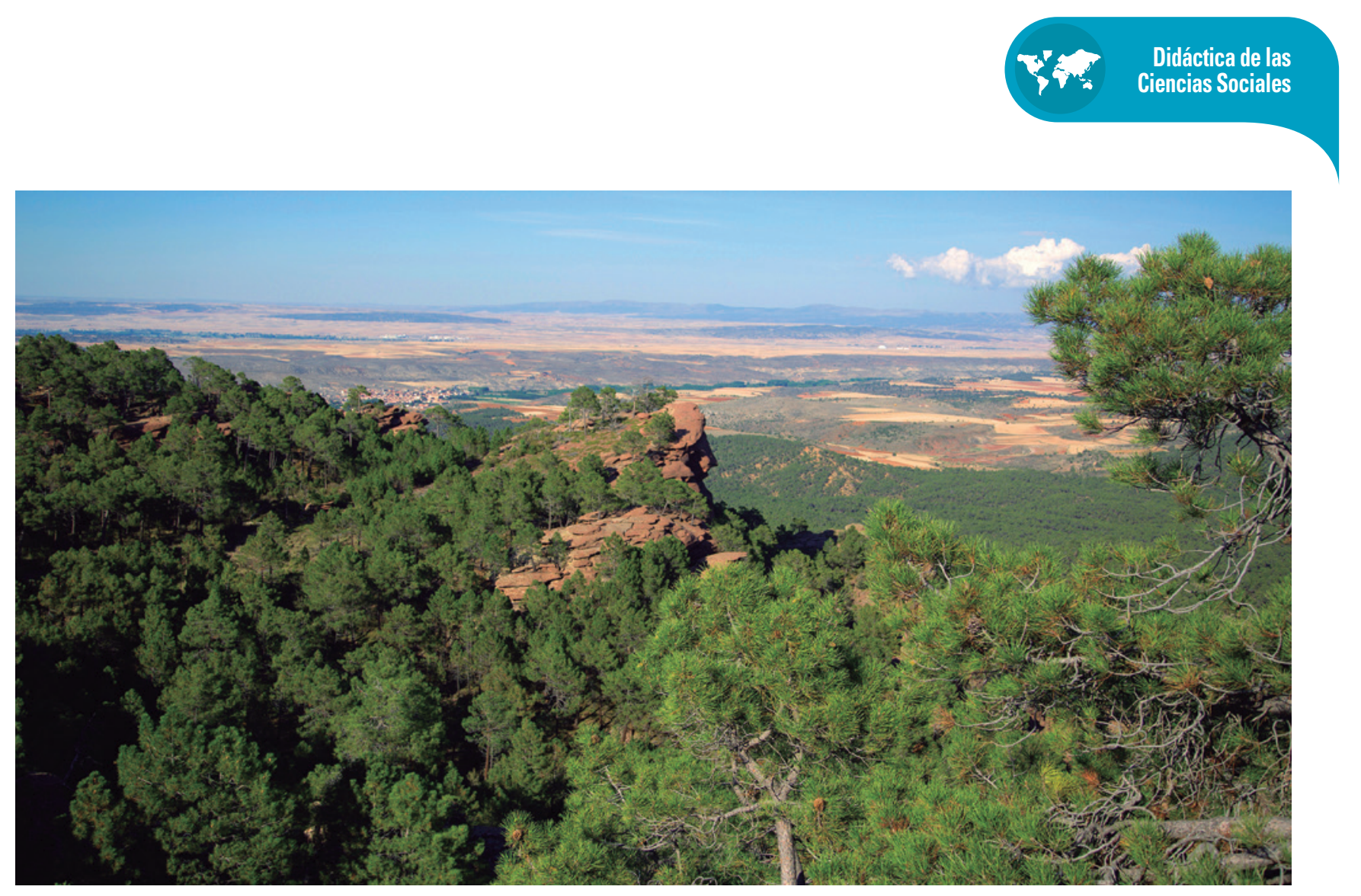

ellos, hecho que facilita la construcción del conocimiento, pues conlleva considerarse parte del objeto de estudio.

$\boldsymbol{\lambda}$ Los paisajes son una realidad tangible que se observa y de la que se obtiene información de forma directa. Su ubicuidad los convierte en objeto de observación en todo momento, por lo que el aprendizaje trasciende el ámbito del centro y pone en práctica el uso de todos los sentidos.

$\boldsymbol{\lambda}$ No existe un modelo concreto, sino que presentan una enorme diversidad, por lo que cada paisaje aporta nuevos conocimientos.

7 Poseen elementos y valores que pueden suponer un aliciente al abordar su estudio: valores arqueológicos, botánicos, arquitectónicos, paleontológicos, etc.

7 Son entes dinámicos en los que no cesan las actividades.

7 El estudio del paisaje permite aplicar multitud de enfoques metodológicos.

入 Indagar en los paisajes supone poder comprender las relaciones que se establecen entre lo global y lo local.

\section{El paisaje como contenido curricular}

El paisaje ha formado parte de los currícula de los diferentes niveles educativos desde hace décadas, si bien no siempre desde la perspectiva del CEP. Enmarcado bajo conceptos como medio, medio social, entorno o espacio geográfico, los objetivos y procedimientos establecidos siguen la línea actual. La evolución de su concepción en el seno de la Geografía y de otras ciencias afines ha venido trasladando a la educación los nuevos enfoques para su enseñanza y aprendizaje. De modo que el "medio" o "entorno" se contemplaron como paisaje añadiendo la consideración de todos los espacios, incluso los coti-

Ilustración 1. Componentes y esquema del estudio del paisaje

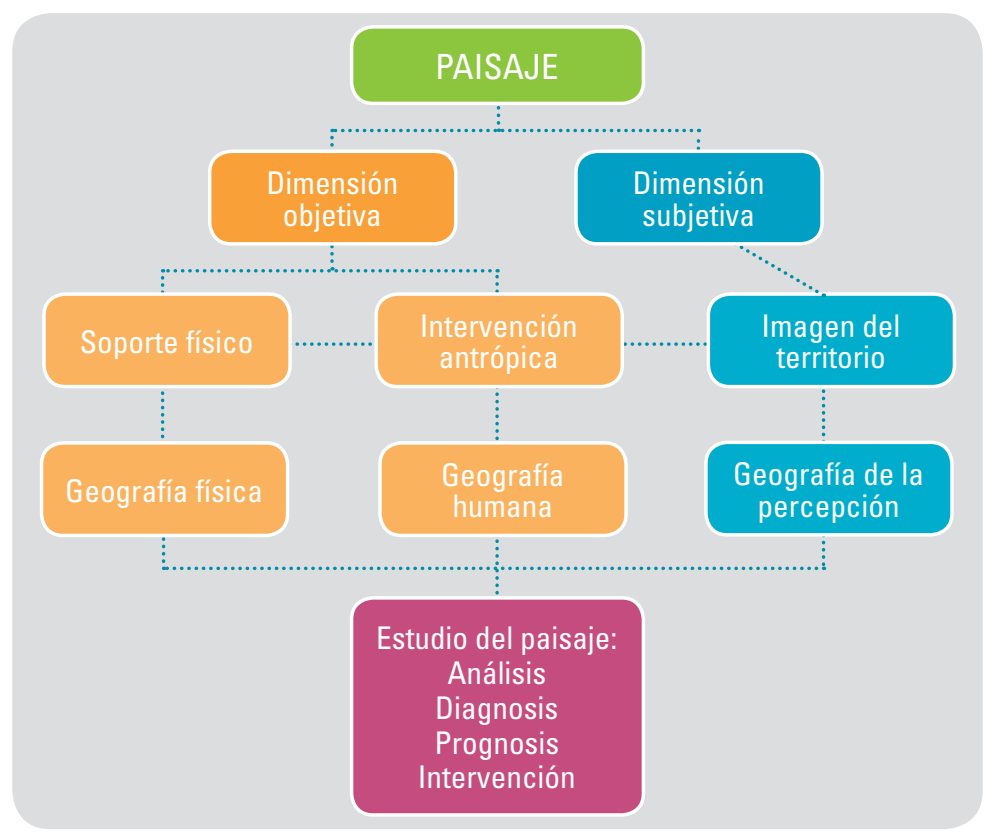

La figura de paisaje protegido acoge espacios merecedores de protección especial por sus valores naturales, estéticos y culturales. Pinares de Rodeno (Teruel) 
A través del Comparador PNOA del Instituto Geográfico Nacional (https://wwwign. es/web/comparador_pnoa/index.html), podemos visualizar dos ortofotos de un paisaje realizadas en diferentes momentos. En el ejemplo de arriba vemos el municipio de Ea (Vizcaya) en 1957 (vuelo americano serie B) a la izquierda y en 2017 (PNOA) a la derecha. Después respondemos razonadamente a las siguientes cuestiones: ¿qué elementos naturales componen el paisaje?, ¿qué tipo de paisaje es?, ¿qué formas del relieve podemos identificar?, ¿cómo es la vegetación?, ¿cómo desemboca el río?, ¿cuál es la tipología del poblamiento?, ¿qué infraestructuras podemos identificar?, ¿qué actividades económicas pueden darse en la zona?, ¿qué cambios observamos en la imagen actual respecto a la de los años cincuenta: en la vegetación, en los cultivos, en el municipio....?

Esta actividad está relacionada con el estándar de aprendizaje evaluable 5.1. Clasifica los principales paisajes humanizados españoles a través de imágenes del área de Ciencias Sociales de primer ciclo de ESO.

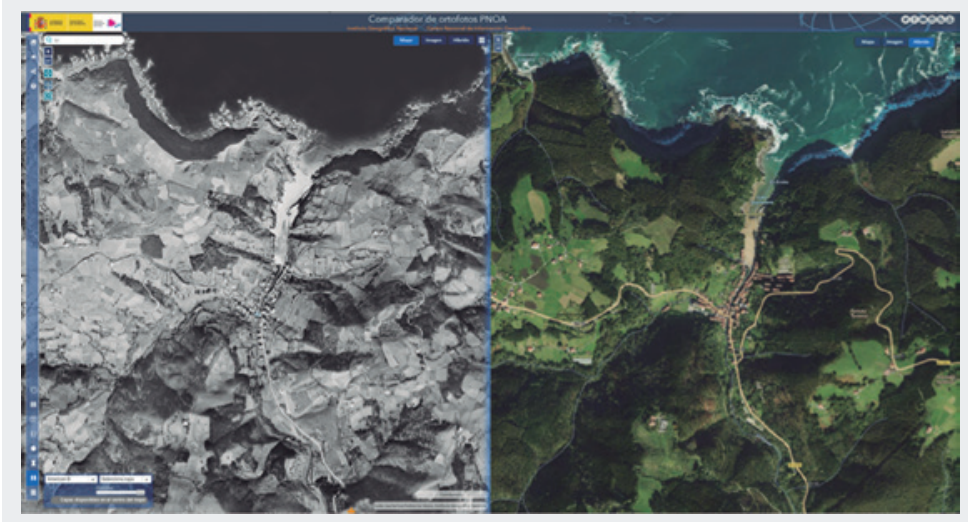

Vista del Comparador PNOA del IGN

\section{Si aprender es el recurso de la inteligencia para}

\section{sobrevivir en un mundo cambiante, entonces}

comprender y conocer los paisajes ha de ser

un objetivo de primer orden para la educación
geográfica

dianos y los degradados. Sin embargo, la concepción de paisaje que mana de los actuales currícula de los diferentes niveles educativos y las distintas autonomías no abarca la totalidad de las dimensiones que el CEP le otorga. La base subjetiva, la percepción del territorio, que es la esencia del concepto, apenas se aborda en los contenidos. Hecho que conlleva una visión externa desde la que observar y ana- lizar paisajes naturales, rurales, urbanos, industriales o turísticos sin que el sujeto constituya parte de aquello observado y analizado.

Los actuales decretos que establecen las enseñanzas mínimas de la Educación Primaria, Secundaria Obligatoria y Bachillerato, contemplan al paisaje en sus contenidos, vinculado a las áreas de Ciencias de la Naturaleza y Ciencias Sociales y dentro de estas últimas a la Geografía. En el segundo ciclo de Educación Infantil, el acercamiento al paisaje se realiza desde el área de conocimiento del entorno, con el objetivo de desarrollar la capacidad de "conocer y valorar los componentes básicos del medio natural y algunas relaciones, cambios y transformaciones, desarrollando actitudes de cuidado, respeto y responsabilidad en su conservación" (Real Decreto 1630/2006). En el área de Ciencias Sociales de Educación Primaria, el concepto paisaje forma parte de los contenidos del bloque 2: El mundo en que vivimos. En él "se identifican los elementos del paisaje (relieve, clima, hidrografía...) y se describen y caracterizan los principales medios naturales y su localización". En cuanto a los contenidos que hacen referencia al paisaje en los decretos y órdenes por los que se establece el currículo de Educación Primaria de las diferentes comunidades autónomas, varían sustancialmente de unos casos a otros. De todos podemos extraer diez líneas principales de contenidos: componentes; valoración y conservación; acciones de mejora; tipología básica; intervención humana; imagen cultural; paisaje local; de la comunidad autónoma; de España y, por último, paisajes de Europa.

El Real Decreto 1105/2014, por el que se establece el currículo básico de la Educación Secundaria Obligatoria, contempla el paisaje en los contenidos de las asignaturas troncales de Geografía e Historia y Biología y Geología, en el primer ciclo de los dos que comprende la etapa. En el ámbito de Geografía e Historia, hace referencia al concepto en los dos bloques de contenidos en los que se estructura la asignatura: El medio físico y El espacio humano. En el pri- 
mer bloque el acercamiento al concepto de paisaje se realiza desde su dimensión natural, como resultado de los componentes bióticos y abióticos de la tierra como el clima, el relieve o la vegetación. Se estudia por lo tanto el paisaje natural. En el segundo, El espacio humano, se concibe el paisaje como resultado de las actividades económicas, de lo que resulta una clasificación en función de los componentes productivos dominantes: paisajes agrarios, industriales, turísticos o urbanos.

En cuanto a los contenidos que hacen referencia al paisaje en los decretos y órdenes por los que se establece el currículo de Educación Secundaria de las diferentes comunidades, pueden extraerse once líneas principales de contenidos: medio físico y paisajes de Europa; medio físico y paisajes de España; medio físico y paisajes de la comunidad autónoma; componentes; el paisaje como constructo humano; impacto humano sobre el paisaje natural; tipos de paisajes humanizados españoles; de la comunidad autónoma; según actividad económica: urbanos, rurales, agrarios e industriales.

El actual decreto por el que se establece el currículo básico de Bachillerato tiene como objetivo fundamental para la asignatura optativa de Geografía en Bachillerato: "dar una interpretación global e interrelacionada de cada fenómeno geográfico así como ofrecer los mecanismos que sirvan para dar respuestas y explicaciones a los problemas que plantea el territorio de España" (R. D. 1105/2014). En él se considera al paisaje, y las actividades que se desarrollan sobre el territorio, como el objeto de estudio de la Geografía. Los contenidos de la asignatura están organizados en doce bloques, de los cuales once se circunscriben al territorio español, abordando en el duodécimo y último las relaciones de nuestro país con Europa y el mundo. Los cinco primeros bloques abordan aspectos de geografía física y "contienen los conocimientos básicos para la construcción del conocimiento geográfico del país y para explicar la variedad de paisajes de España" (R. D. 1105/2014). Los seis siguientes se ocupan

\section{ÁCORA DE DROFESORES}

Recursos didácticos para educar en paisaje

En el estudio de los paisajes podemos utilizar numerosos recursos didácticos: el lenguaje cartográfico, las salidas de campo, las encuestas, la fotografía, bases de datos climatológicos, obras literarias, etc. De todos ellos las salidas de campo, organizadas en itinerarios didácticos en los que el alumnado va descubriendo el paisaje a través de la observación, son, sin lugar a dudas, el mejor de los recursos para alcanzar un aprendizaje autónomo y significativo.

Gracias a las tecnologías de la información geográfica (TIG), Ios visualizadores de cartografía digital o los sistemas de información geográfica (SIG) entre otros, la cartografía digital supone en la actualidad una herramienta idónea para interpretar el paisaje, al tiempo que contribuye positivamente al desarrollo de la competencia digital, tan necesaria para la inserción en el ámbito laboral. La posibilidad de consultar numerosas capas de información cartográfica — vegetación, litología, topografía, hidrografía, usos del suelo, etc.— referidas a un mismo territorio, permite realizar un análisis completo de los componentes del paisaje. En este sentido, algunas herramientas como Iberpix (https://www.ign.es/iberpix2/visor/) del Instituto Geográfico Nacional, con interfaces sencillas e intuitivas, permiten diseñar actividades adaptadas a estándares de aprendizaje de Geografía de Educación Primaria, ESO 0 Bachillerato.

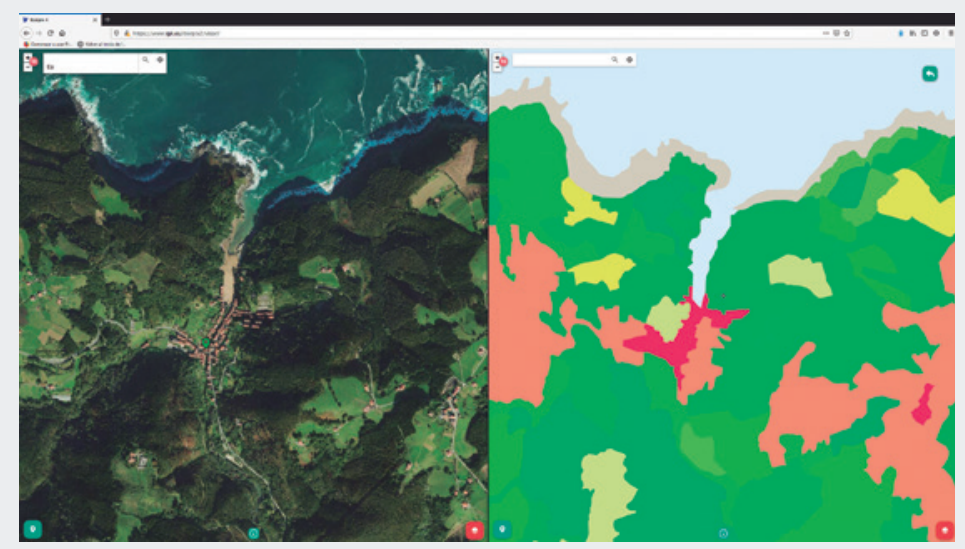

Ortoimagen y mapa de usos del suelo que permiten identificar fácilmente los componentes del paisaje del municipio de Ea (Vizcaya)

de la geografía humana y de los paisajes intervenidos o creados por el ser humano.

De los contenidos de la asignatura en los distintos decretos autonómicos se pueden establecer la siguientes líneas principales: el paisaje como resultado cultural; paisajes asociados a las diferentes litologías; diversidad de paisajes naturales españoles; de la comunidad autónoma; clasificación bioclimática de los paisajes españoles; formaciones vegetales; interacción humana con el paisaje y sus consecuencias; los paisajes agrarios españoles; los paisajes agrarios de la comunidad autónoma; espacios turísticos; espacios urbanos; los paisajes urbanos 
Paisajes en familia

El paisaje siempre está presente en nuestras vidas. El habitado cotidianamente 0 el de tiempo de vacaciones, el familiar 0 aquel de los viajes contemplado fugazmente a través de la ventanilla. Comentar sus componentes, incluso desde el juego, es una actividad formativa que trasciende al ámbito formal. La realización de cuadernos de viaje en los que describir los paisajes, sus componentes físicos y su paisanaje supone una de las mejores maneras de educar la mirada. Diarios que bien pueden completarse con fotografías y mapas, esbozos y datos de interés, incluso con anécdotas. Algunas preguntas que podemos plantear acerca de cualquier escenario contemplado son: ¿qué rocas forman el relieve?, ¿cómo es ese relieve?, ¿cuál es la vegetación dominante?, ¿cómo aparece el agua en el paisaje?, ¿cómo lo ha modificado el hombre?, ¿qué elementos ha incorporado?, ¿a qué se dedican sus habitantes?, ¿qué culturas ya desaparecidas dejaron su huella en él?, ¿qué impactos negativos identificamos?, ¿está perdiendo su funcionalidad?

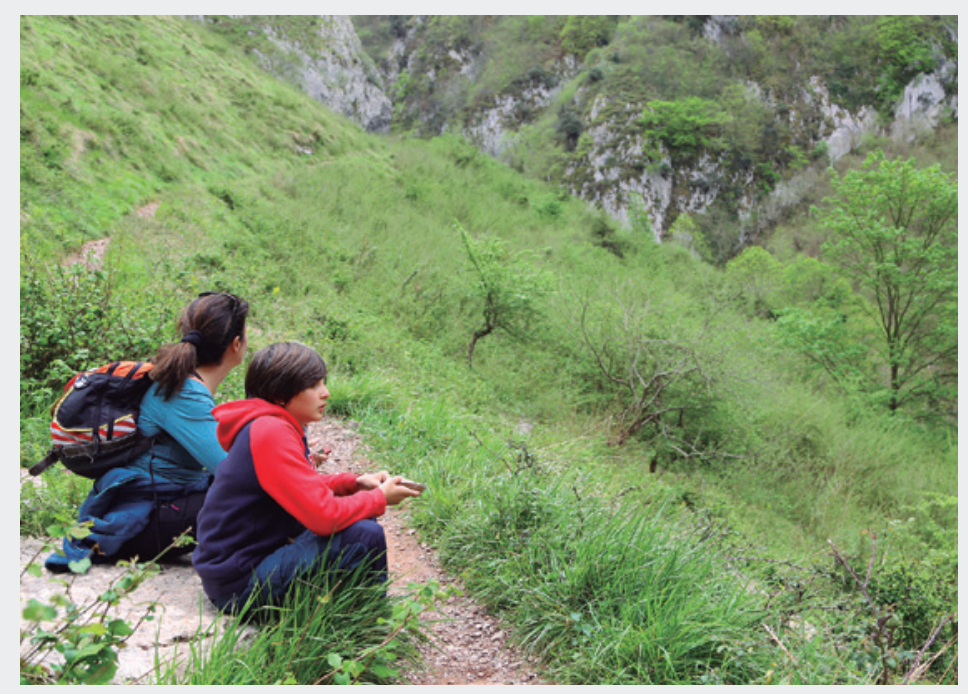

El contacto directo con el paisaje es la mejor manera de aprender Geografía. Ruta de las Xanas (Asturias).

\section{La educación debe contribuir con la formación de una ciudadanía, sensibilizada e implicada, que pueda valorar y participar en las acluaciones que se planteen sobre el territorio}

de la comunidad autónoma; paisajes industriales; los paisajes industriales españoles; comentario de paisajes rurales españoles; influencia histórica en el paisaje de las ciudades españolas; la dimensión temporal del paisaje.

\section{Conclusiones}

Como recoge el CEP, el paisaje es un elemento básico de la calidad de vida de las personas. Es además patrimonio natural y cultural y, por lo tanto, recurso económico. Por todo ello, se hace necesaria la educación en paisaje, entendida como el desarrollo de la capacidad para interpretar y valorar el territorio y su imagen. Conscientes de esta realidad, el paisaje es un contenido curricular del área de Ciencias Sociales que se aborda en todas las etapas. Desde la didáctica supone un recurso de primer orden, pues permite comprender los hechos geográficos relacionados entre sí como componentes de un geosistema sobre el cual el hombre desarrolla su actividad. Así, la Geografía, como ciencia que enseña a pensar el espacio, es el entorno idóneo para promover la educación en paisaje •

Crespo, J. M. (2019). El visualizador Iberpix 4 del Instituto Geográfico Nacional: un recurso didáctico para la interpretación de los componentes físicos del paisaje. Enseñanza de las Ciencias de la Tierra, 27(2), 182-191.

García de la Vega, A. (2018). Reflexiones sobre educación geográfica. Revisión disciplinar e innovación didáctica. Madrid: Ediciones de la Universidad Autónoma.

LiCERAS, A. (2003). Observar e interpretar el paisaje. Estrategias didácticas. Grupo Editorial Universitario.

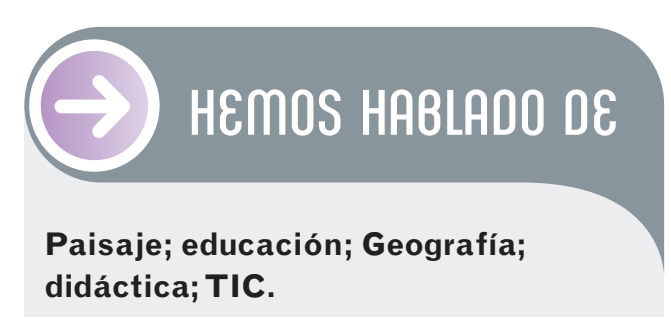

Este artículo fue solicitado por PADRES Y MAESTROS en marzo de 2020, revisado y aceptado en junio de 2020. 